\title{
Participation Research of Virtual Learning Community
}

\author{
Ju-mei Zou ${ }^{1, a}$, Jian-ping Zhang ${ }^{1, b}$ \\ ${ }^{1}$ College of Education, Zhejiang University, Hangzhou, China \\ aEmail:Jumeiz@163.com, b21zjp@vip.163.com
}

\begin{abstract}
Keywords:Virtual learning community, Participation, Continued involvement
\end{abstract}
Abstract. Firstly, the definition and implication of virtual learning communities (VLCs) are introduced, then the research on definition, dimension and process of participation of VLC members and their continued involvement are presented. Finally, based on the review of literatures about VLCs, we analyzed the problems existed currently and proposed the developing directions of the participation research of VLC members in the future.

\section{Introduction}

Now, virtual communities (VCs) are very popular and have been extensively applied in many fields, such as sociology, education, recreation, and so on. However, the most important of their applications are in learning and education fields, and thoseVCs with the aims of learning and education are then called virtual learning communities (VLCs)[1].

VLCs in this paper arequite different from general VCs although there are some commences between them. Only if the members are absorbed in learning and practice, the VCs thus become the tools to connect the membersof theirs. In these VLCs, members can share their experiences, knowledge and stories, and then the communities become learning organizationswhich are useful for speeding up the members' learning. So, Dr. Gan said that VLCs are the combination of online learning and traditional VCs [2].

\section{Definition and implication of VLCs}

The definition of VLC is complicated due to its extensive applications in fields of education, philosophy, sociology, communication, computer science, and so on. In this paper, the definition of VLC defined by Carlén is adopted, i.e., it is a type of interpersonal community and learning environmentformed during the learning process of under the network environment [3], where there are two meanings of VLC. One is that VLC is one kind of learning organization formed with the help of technology. A group of people communicateusinginformation techniques as mediaand take part in some activities based on cooperation and learner-centered. VLC is a group that aims to promote the collective knowledge creation while the members share their own practice and values to each other; the other is that VLC is a online learning environmentinvolving some hardware (such as internet-based distance education support platform) and some software (such as policies, culture, institutions and the sum of teacher resource and academic atmosphere), and it also isa system maintaining the atmosphere and circumstances of the members' learning process. 


\section{Implication of participation}

Participation is a word used frequently in our ordinary language. It is explained in Grand Chinese Dictionary that participation is also called involvement or attendance, that is to say hear first and then take part in the event, while the explanation in Modern Chinese Dictionary is to take part in the plan, discussion and treatment of events. The verb corresponding to participation is participate, the meaning of it is share in something or become a participant, be involved in. And, the noun,participation,means the act of sharing in the activities of a group or the condition of sharing in common with others (as fellows or partners etc.). We can define and analyze this word from different angles.Generally, the acts aiming to excite all the people in attendance to take part in events and to provide them chances to experience, explore, express and communicate can be called as participation.

"Participation", the concept has been usedwidely in modern management and organizational behavior fields, it means to individually intervene, devote, or be involved in certain state, it is the process in which principal part affects the activities actively, and is also the unificationof ability and inclination. According to the cognitive strategies used by learners, participation behaviors are divided into surface or deep participation by Pintrich. For the former, it is the explicit expression of behavior showing a kind of simply drill or practice, and its cognitive strategy is on the level of lowness; while for the latter, it is a kind of creation, introspection or self-control behaviors.Marks defined participation a psychical process, especially involving attention, hobbies, devotion and effort during the learning process, which includes emotion and behavior participations. However, cognitive participation and emotional participation are both based on behavior participations.

\section{Dimensions of participation}

A number of studies have attempted to analyze the participation behaviors of community members withdifferent dimensions.

Armstrong and Hagel identified four groups, based on the participation degree and values of community members. The four types of members are: viewers, lurker, contributors and buyers. Viewers are the fresh members who browse the web aimlessly with lowest value. Lurkers are the members who stay in the community for a long time but have not contributed their own creation. However, we can still collect some useful information about them, such as theirbrowsing path, personal data, etc. The value of them is higher than that of viewers. Contributors, who are evolved from some divers, usually have enthusiasm for VCs and actively contribute their own writings. They stay in VCs for a longer time, and the values of them are the second high. For the last type, buyers, who take active part in the VCs and buy the products or services, are the most valuable members. They not only bring income but also sponsors or advertisers for the VCs.

While Adler and Christopher classified the VC members into another four types according to their participatory approaches: passives who want to get entertainment or information without effort; active persons who take active part in the games or discussion sponsored by others; sponsors who sponsor discussion topic or plan activities to attract other members to participate; administrators who are the intermediary between VC members and managers, usually, they are experienced sponsors, such as webmaster.

Bomm and Clarke thought that customers join VCs due to their assignments, such as search information and they join VCs is because they want to get information or others' experience. They 
also proposed the opinion that the richness of information provided by VCs greatly affects the members' wishes to join the VCs activities.

Nonneck and Preece believed browsing website and posting writings are the main behaviors of the members of VCs. Koh et.al. thought that the typical interaction of media-based VCs is to share information or news, solve problems and generally communicate, and all these activities are mainly carried out in form of browsing website or posting writings, so these two behaviors are the main elements of all VCs.

Participation behaviors of VC members were classified into four types by Mathwick, namely the exchangeable, informational, sociable and egoistic. For the first ones, they have specific orientation for the information exchange and social intercourse; for the second ones, they focus on the information searching and seldom contact with others; for the third ones, they regard the contact and communications with others as very important, searching information is only the assistant function; for the last ones, there is not highlight for the information exchange and social intercourse, it is just for ego needs to join VCs. The property of the four kinds of participation behaviors can be described as shown in Fig. 1.

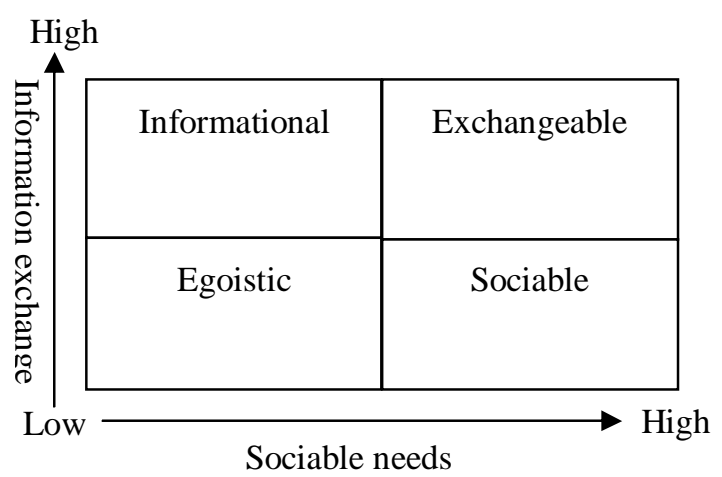

Fig. 1 Participation behaviors for on-line VCs.

Ridings, et al., summarized the participation behaviors based on Mathwick's work, they classified the behaviors into two types: Lurking and Posting. Although not directly contributing to the community, lurking in the VC can also be seen as a form of passive participation. Lurkers are the persons who mainly search information but not actively join the VC activities; posters are the participators who actively take part in VC activities with high social needs to VCs.

The study on participation behaviors of VC members can be summarized as described in table 1 .

Table 1.Participation dimensions of VC members.

\begin{tabular}{lll}
\hline Researchers & Study Perspective & Dimensions \\
\hline Armstrong and Hagel (1997) & Participation degree and value & $\begin{array}{l}\text { Viewer, aquanaut, contributor, } \\
\text { buyer }\end{array}$ \\
$\begin{array}{l}\text { Adler and Christopher } \\
\text { (1998) }\end{array}$ & Participation approach & $\begin{array}{l}\text { Passives, active person, } \\
\text { sponsors, administrators }\end{array}$ \\
Nonnecke and Precce (2000) & Participation approach & View, post \\
Mathwick (2002) & $\begin{array}{l}\text { Information exchange and } \\
\text { Social needs }\end{array}$ & $\begin{array}{l}\text { Exchangeable, informational, } \\
\text { sociable,egoistic }\end{array}$ \\
Wang and Fesenmaier (2004) & Belongingness for VCs & Time, interaction \\
Ridings, et al. (2006) & Participation approach & Lurker, poster \\
\hline
\end{tabular}




\section{Processes of participation}

Generally, one will join a VC when he or she wants to get some experience by using internet or it is interested in some VC activities, then he or she will be integrated into the community by interacting with others or learning from each other. During the process, the member would change his or her role and behaviors. Kozinetsl described the participation process of VC members, as shown in Fig. 2. Owing to the formation of $\mathrm{VC}$ is closely related with the participation of individuals, the figure also embodies the construction and formation process of VCs.

\begin{tabular}{llll}
$\begin{array}{l}\text { Topic } \\
\text { information } \\
\text { exchange }\end{array}$ & $\begin{array}{l}\text { Cultural rules } \\
\text { (language and } \\
\text { concept) } \\
\text { information } \\
\text { exchange }\end{array}$ & $\begin{array}{l}\text { Acceptance and } \\
\text { Cultural rules }\end{array}$ & $\begin{array}{l}\text { Cultural } \\
\text { cohesion }\end{array}$ \\
\hline \multicolumn{4}{c}{ Time and communication } \\
$\begin{array}{l}\text { Identification } \\
\text { information } \\
\text { exchange }\end{array}$ & $\begin{array}{l}\text { Struggle of } \\
\text { power and } \\
\text { position }\end{array}$ & $\begin{array}{l}\text { Impression } \\
\text { formation }\end{array}$ & Relationship \\
\hline
\end{tabular}

Fig. 2 participation processes of VC members.

\section{Continued participation behavior}

Continued participation behavior of VCs has been studied from the angle of time dimension. It is worth to be researched because participation of VC members is a continued process. As time goes on, VCs develop and change by themselves, and the sole or behaviors of members would change, then the motivation to join VCs of members' would subsequently change. Additionally, the development of VCs depends on the continued participation of members which represents the loyalty of members to VCs and is the base of existence and development of VCs.

The continued using for information technology was divided into three types by Guinea and Markus [5]:

1) to analyze the continued using behaviors from the angle of rational decision making involving belief, hope and experience, ones believe that continued using is based on the rational evaluation of users to information technology, such as perceived usefulness or ease.

2) to analyze the continued using behaviors from the angle of emotion instead of perception, ones decision of continuance using mainly depends on emotions, such as satisfaction or other factors.

3 ) to analyze the continued using behaviors from the angle of habits, ones think under a certain circumstance, the base of continuance using if not perception or emotion but habit, which mainly affected by circumstance and the unconscious repetition behavior intention.

Zhang studied the effect of psychological safety on the continuance episteme sharing behavior and found that the former has significant influence on the latter indeed [6]. Additionally, belief and self-awareness were included to the study model, and it was found that belief affects on continuance episteme sharing by psychological safety while self-awareness has negative effect on the perception of psychological safety.

Considering cognition and emotion, Wang et al. analyzed the continuance using behaviors of Facebook members from the angle of computer self efficacy, and found the effects of general and 
special computer self efficacy are not all same, they both depend on the using experience of computer or Fackbook software [7].

Shi et al. studied the main motivations of users for social web service and the continued using behaviors of Fackbook users based on the theory of expected inconsistency[8]. The assumption of the work is that the motivations of users include off-line contact, making new friends, getting information and recreation. The expectation to these four factors disagrees with the final performance, which would affect the satisfaction of users, and then affect the continuance using of users. Experimental results show that user satisfaction is the key factor of continued using, and the formation of user satisfaction is affected by the disagreement among off-line contact, information obtaining and recreation.

Fang studied the factors combining belief and justice theory[9]. The assumption is that . All the assumptions are proved by the experimental results obtained from the study on a certain VC in Tai Wan.

\section{Future research}

Based on the reviews above, we have a better understanding on VLCs, participation behaviors, and other related research. All these works laid the foundation of theory and practice research for the continuance participation of VC members. The problems existed currently and the potential research in the future can be concluded as following:

1) For the study of participation behaviors of VLC members, the research perspectives have changed from integration to classification. Currently, the definition of participation behaviors of VLC members is single dimension, which includes information sharing, browse, attending VC activities, and so on. In the future, the research of participation behaviors will be fractionized, for example to discriminatethe participation quantity or quality, request or contribution, seldom or core participation, and to study the participation motivations and mental mechanism corresponding to these behaviors, which is useful for distinguishing the internal driving force for certain participation behaviors.

2) To deeply study dynamic evolution of participation motivation of VLC members. Lots of work have been done outside of China, and some models were proposed and studied. While in our country just simple and scattered classification has been done with different results due to different classification criteria. These work only focused on the reason analysis without motivation evolution or variation. Majorworks were done by surveying the cross section data ignoring the internal or external motivations and function of VLC members during the participation process, possible variation of social benefit, which weakens the related research results to explain the mental mechanism of participation behaviors of VLC members. Therefore, it is very important to plan the inspiration strategies for participation behaviors in VLCs by analyzing longitudinal data obtained from VCs, effectively discriminating freshman or veteranparticipant, and investigating the interaction effect between internal or external motivation and participation behaviors.

3) To study the effect of real/virtual relationship on the participation behaviors of VLC members. A new perspective of $\mathrm{VC}$ research was provided by the introduction of social capital theory, but the existed social capital research are almost based on network questionnaire, and social network analysis approach can just explain the characters of interaction relationship of VCs, but seldom studies have combined these two approaches. In the future, it is necessary to combine them to thoroughly investigate social capital based on real/virtual community interaction relationship, and to explain the participation motivations and behaviors of VC members hidden in the community 
relationship network.

\section{References}

[1] F. Hu, A brief discussion on the educational virtual community, Audio-visual education research,2005(9): 42-46.(In Chinese)

[2] Y. Gan, Analysis and research on the multiple connotation of virtual learning community, Modern Distance Education Research, 2005(5): 10-15. (In Chinese)

[3] U. Carlén, Typology of online learning communities, First International Conference on Net Learning, Ronneby, Sweden, 2012.

[4] A.O.d. Guinea, M.L. Markus, Why break the habit of a lifetime? Rethinking the roles of intention, habitand emotion in continuing information technology use, Mis Quarterly, 2009, 33(3):433-444.

[5] Y. Zhang, Y. Fang, K. K. Wei, Exploring the role of psychological safety in promoting the intention to continue sharing knowledge in virtual communities, International Journal of Information Management, 2010, 30: 425-436.

[6] D. Wang, L. Xu, H.C. Chan, Understanding users' continuance of facebook: the role of general and specific computer self-efficacy, The Twenty Ninth International Conference on Information Systems, Paris, France, 2013.

[7] N. Shi, M.K.O. Lee, C.M.K. Cheung, et al, The continuance of online social networks: how to keep people using facebook ? The 43rd Hawaii Intemational Conference on System Sciences, Hawaii, 2010.

[8] Y. Fang, D. Neufeld, Understanding sustained participation in open source software projects , Journal of Management Information Systems, 2009, 25(4): 9-50. 